\title{
Hydrogen Incorporation in Natural Mantle Olivines
}

\author{
Jed L. Mosenfelder', Thomas G. Sharp ${ }^{2}$, \\ Paul D. Asimow ${ }^{1}$, and George R. Rossman ${ }^{1}$
}

Constraints on water storage capacity and actual content in the mantle must be derived not only from experimental studies, but also from investigation of natural samples. Olivine is one of the best-studied, OH-bearing "nominally anhydrous" minerals, yet there remain multiple hypotheses for the incorporation mechanism of hydrogen in this phase. Moreover, there is still debate as to whether the mechanism is the same in natural samples vs. experimental studies, where concentrations can reach very high values (up to $\sim 0.6 \mathrm{wt} \% \mathrm{H}_{2} \mathrm{O}$ ) at high pressures and temperatures. We present new observations and review IR and TEM data from the literature that bear on this question. Hydrogen incorporation in natural olivine clearly occurs by multiple mechanisms, but in contrast to some previous assertions we find that there are strong similarities between the IR signatures of experimentally annealed olivines and most natural samples. At low pressures (lower than $\sim 2 \mathrm{GPa}$ ) in both experiments and natural olivines, hydrogen incorporation might be dominated by a humite-type defect, but the nature of the defect may vary even within a single sample; possibilities include point defects, planar defects and optically detectable inclusions. IR bands between 3300 and $3400 \mathrm{~cm}^{-1}$, ascribed previously to the influence of silica activity, are apparently related instead to increased oxygen fugacity. At higher pressures in experiments, the IR band structure changes and hydrogen is probably associated with disordered point defects. Similar IR spectra are seen in olivines from xenoliths derived from deeper parts of the mantle (below South Africa and the Colorado Plateau) as well as in olivines from the ultra-high pressure metamorphic province of the Western Gneiss Region in Norway.

\section{INTRODUCTION}

The existence of structurally bound hydroxide $(\mathrm{OH})$ groups in natural olivine crystals was established by spectroscopic investigation over 35 years ago [Beran, 1969]. The importance of nominally anhydrous minerals such as olivine as storage sites for water (in the form of trace amounts

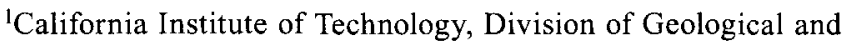
Planetary Sciences, Pasadena, California, USA

${ }^{2}$ Department of Geology, Arizona State University, Tempe, Arizona, USA

Earth's Deep Water Cycle

Geophysical Monograph Series 168

Copyright 2006 by the American Geophysical Union.

10.1029/168GM05 of hydrogen) in the mantle was suggested soon thereafter [Martin and Donnay, 1972]. This hypothesis is now widely accepted, largely as a result of work on natural samples [e.g., Beran and Putnis, 1983; Miller et al., 1987; Bell and Rossman, 1992] as well as experimental studies at high pressures and temperatures [e.g., Mackwell et al., 1985; Bai and Kohlstedt, 1992; 1993; Kohlstedt et al., 1996]. Several review papers are now available on this topic [Rossman, 1996; Ingrin and Skogby, 2000; Bolfan-Casanova, 2005]. As testified to by the papers in this volume, it is also now recognized by workers in multiple disciplines across Earth science that trace amounts of hydrogen can profoundly affect a variety of geophysical processes, including deformation, melting, electrical conductivity, and the propagation of seismic waves. 
As a result of the scarcity of very high-pressure natural samples as well as the possibility of sample alteration during ascent to the surface [Demouchy et al., 2006; Peslier and Luhr, 2006], our view of water storage capacity throughout the upper mantle [e.g., Hirschmann et al., this volume] is informed primarily by experimental studies. Much of the attention in this field has been focused on olivine, the predominant mineral of the upper mantle. However, recent work has highlighted potential discrepancies between earlier experimental work and nature with regard to mechanisms of hydrogen incorporation in olivine [Matveev et al., 2001; Lemaire et al., 2004; Berry et al., 2005; Matveev et al., 2005; for a contrasting view see Mosenfelder et al., 2006]. Differences in opinion among various research groups may lead to confusion for the wider audience interested in water storage in the mantle. Our intent is not to provide a complete review of this topic but to highlight the most important issues raised by recent studies, as well as present some new observations on natural $\mathrm{OH}$-bearing mantle olivines.

\section{METHODS}

As part of this study, we reinvestigated some of the samples originally surveyed by Kitamura et al. [1987] and Miller et al. [1987]. Results on some of the samples prepared for the latter study (particularly GRR1629 and infrared (IR) spectra of CIT15089a and CIT15089b) have not been previously published. In addition, new samples from the Buell Park and Green Knobs localities (Arizona, USA) and from Alpe Arami (Central Alps, Switzerland) were prepared for examination using Fourier-transform infrared spectroscopy, optical microscopy, electron microprobe analysis (EMPA), and transmission electron microscopy (TEM). Table 1 lists the sample localities,

TABLE1. Samples studied

\begin{tabular}{|c|c|c|c|c|c|c|}
\hline Sample \# & Locality & Occurrence (host) & IR bands ${ }^{\mathrm{a}}$ & $\begin{array}{r}\mathrm{ppm} \\
\mathrm{H}_{2} \mathrm{O}^{\mathrm{b}}\end{array}$ & Features ${ }^{c}$ & Reference $^{\mathrm{d}}$ \\
\hline GRR949 & $\begin{array}{l}\text { Almklovdalen, } \\
\text { Norway }\end{array}$ & UHP peridotite body & (I), Ia, serp & $20^{\mathrm{e}}$ & Lily pads, Mt inclusions & 1 \\
\hline CIT15089a & $\begin{array}{l}\text { Almklovdalen, } \\
\text { Norway }\end{array}$ & UHP peridotite body & I, Ia, serp & 26 & Lily pads, Mt inclusions & 1 \\
\hline CIT15089b & $\begin{array}{l}\text { Almklovdalen, } \\
\text { Norway }\end{array}$ & UHP peridotite body & I, Ia, serp & $23^{\mathrm{e}}$ & Lily pads, Mt inclusions & 1 \\
\hline GRR999a & $\begin{array}{l}\text { Zabargad Island, } \\
\text { Egypt }\end{array}$ & $\begin{array}{l}\text { hydrothermal vein in } \\
\text { peridotite }\end{array}$ & Ia, humite? & 14 & Clear & 2 \\
\hline GRR1001 & Morales, Mexico & basalt & Ia, II & 14 & Clear & 3 \\
\hline GRR1006 & $\begin{array}{l}\text { Monastery Farm, } \\
\text { South Africa }\end{array}$ & kimberlite & I, Ia & $61^{\mathrm{e}}$ & Ti-Chu inclusions & 3 \\
\hline GRR 1007 & Vesuvius, Italy & $\begin{array}{l}1776 \text { eruption } \\
\text { leucitite basalt }\end{array}$ & (I), Ia, humite? & 55 & Clear & 3 \\
\hline GRR 1390 & Buell Park, AZ & minette diatreme & $\begin{array}{l}\text { I, Ia, Ti-Chu, } \\
\text { serp }\end{array}$ & 471 & $\begin{array}{l}\text { Clear, orange-brown,Ti-Chu } \\
\text { planar defects }\end{array}$ & 4 \\
\hline GRR1629 & Buell Park, AZ & minette diatreme & I & 39 & $\mathrm{Di}, \mathrm{Chr}$ inclusions & 4 \\
\hline GRR1784a & Buell Park, AZ & minette diatreme & I, Ia, Ti-Chu & 80 & $\begin{array}{l}\mathrm{Di}, \mathrm{Chr} \text { inclusions, Ti-Chu } \\
\text { inclusions and planar defects }\end{array}$ & 4 \\
\hline GRR 1784b & Buell Park, AZ & minette diatreme & I, Ia, Ti-Chu & 188 & $\begin{array}{l}\text { clear, orange-brown, Ti-Chu } \\
\text { planar defects (?) }\end{array}$ & 4 \\
\hline GRR1784e & Buell Park, AZ & minette diatreme & I & 54 & Chr, Di inclusions & 4 \\
\hline GK01 & Green Knobs, AZ & minette diatreme & I, Ia & 54 & Chr, Di inclusions & 5 \\
\hline Alpe Arami & $\begin{array}{l}\text { Alpe Arami, } \\
\text { Switzerland }\end{array}$ & $\begin{array}{l}\text { UHP Alpine } \\
\text { peridotite }\end{array}$ & Ia & 25 & $\mathrm{Ilm}, \mathrm{Chr}$ inclusions & 6 \\
\hline
\end{tabular}

aSee text and Figure 1 for more information; serp = serpentine, Ti-Chu = Ti-clinohumite. $(\mathrm{I})=$ minor component in spectra

bexpressed as ppm by weight, calculated using the Bell et al. [2003] calibration as discussed in text

${ }^{\mathrm{c}} \mathrm{Mt}=$ magnetite, $\mathrm{Di}=$ diopside, $\mathrm{Cr}=$ chromite, $\mathrm{Ilm}=$ ilmenite. "Lily pads" are disk-shaped stress fractures around small inclusions such as chromite or spinel.

${ }^{\mathrm{d}}$ References: 1 = Medaris [1999]; 2 = Beran and Putnis [1983]; $3=$ Miller et al. $[1987] ; 4=$ Kitamura et al. $[1987] ; 5=$ Smith and Levy [1976]; $6=$ Dobrzhinetskaya et al. [1996]

$\mathrm{e}_{\text {value from Kent and Rossman [2002] }}$ 
spectral features, calculated $\mathrm{OH}$ concentrations, inclusion features and references to petrological studies of the localities. Orientation of the crystals was achieved using Raman spectroscopy [see Mosenfelder et al., 2006] and by optical techniques, particularly by identification of growth faces or the $(010)$ cleavage. The uncertainty in orientations is estimated to be $5^{\circ}$ or less. Crystal faces were cut with a wire saw and polished using alumina grinding papers and $0.25 \mu \mathrm{m}$ diamond powder. Olivine in garnet lherzolite from Alpe Arami, collected by the first author during the Fifth International Eclogite Conference, was studied in situ in a $150-\mu \mathrm{m}$ thin section prepared using Crystalbond ${ }^{\mathrm{TM}}$, which was subsequently dissolved from the underlying glass slide using acetone.

FTIR spectroscopy was conducted primarily using the main compartment of a Nicolet Magna 860 spectrometer. We collected polarized, mid-IR spectra from 4000 to $2100 \mathrm{~cm}^{-1}$ at $2 \mathrm{~cm}^{-1}$ resolution by averaging 512 scans, using a GLOBAR infrared light source, a $\mathrm{CaF}_{2}$ beamsplitter, a $\mathrm{LiIO}_{3}$ GlanFoucault prism polarizer, and an MCT-A detector. Circular apertures with diameters of $200-1000 \mu \mathrm{m}$ were used to select analysis areas. For each single-crystal sample, polarized spectra were collected with the E-vector (E) parallel to the [100], [010], and [001] directions (using the same convention for these directions as Bell et al. [2003]). For the Alpe Arami thin section, spectra were collected using an IR microscope on randomly oriented grains and corrected using the procedures outlined in Mosenfelder et al. [2006]. OH concentrations were calculated using the calibration of Bell et al. [2003] applied to three orthogonal spectra, baseline corrected using the procedure outlined in Asimow et al. [2006] and integrated from 3100 to $3700 \mathrm{~cm}^{-1}$. The comparison between this calibration and the more commonly used calibration of Paterson [1982] has been discussed by Bell et al. [2003] and Mosenfelder et al. [2006]. The precision of the absorption coefficient determined by Bell et al. [2003] is $6.5 \%$, but the accuracy of the values in Table 1 also depends on other factors that are difficult to evaluate, such as choice of baseline correction, choice of integration interval and a possible (uncalibrated) dependence of absorption coefficient on wavenumber.

Wavelength-dispersive EMP analyses were obtained using a JEOL 733 microprobe operating at $15 \mathrm{kV}$ (Table 2). Major element analyses were collected using a spot size of $10-\mu \mathrm{m}$ and a beam current of $25 \mathrm{nA}$. For minor and trace elements ( $\mathrm{Ti}, \mathrm{Al}, \mathrm{Mn}, \mathrm{Ca}, \mathrm{Ni}, \mathrm{Na}$, and $\mathrm{Cr}$ ) in olivine, we used a beam current of $300 \mathrm{nA}$ and increased counting times to four minutes on peak and two minutes on background. Detection limits under these conditions are in the range of 10 to $30 \mathrm{ppm}$ (by weight, for the corresponding oxide). Data processing followed the CITZAF method [Armstrong, 1988]. We used well-characterized natural and synthetic standards: $\mathrm{Ni}_{2} \mathrm{SiO}_{4}$, $\mathrm{Mn}_{2} \mathrm{SiO}_{4}, \mathrm{Mg}_{2} \mathrm{SiO}_{4}, \mathrm{TiO}_{2}, \mathrm{Fe}_{2} \mathrm{SiO}_{4}$, albite, microcline and
$\mathrm{Cr}_{2} \mathrm{O}_{3}$. San Carlos olivine with a composition of $\mathrm{Fo}_{90}$ was used as a secondary standard. Note that chemical analyses of some of the olivines in Table 1 have also been published by Kent and Rossman [2002], who additionally analyzed for $\mathrm{P}, \mathrm{Li}$ and $\mathrm{B}$ but not for $\mathrm{Ti}, \mathrm{Cr}$ or $\mathrm{Al}$.

TEM was performed at the Center for High Resolution Microscopy at Arizona State University, using a Philips CM-200 FEG microscope operating at $200 \mathrm{kV}$. Qualitative energy-dispersive chemical analyses were collected using a Kevex EDS detector and an EmiSpec analytical system. The samples for TEM were oriented thin sections mounted to copper grids and thinned to electron transparency by dimpling and Ar-ion bombardment using a Gatan Precision Ion Polishing System with an acceleration potential of $5 \mathrm{KeV}$ and an incidence angle of $5^{\circ}$.

\section{INFRARED SIGNATURES OF NATURAL OLIVINE CRYSTALS}

Infrared spectroscopic studies of olivines have revealed a large number of variably occurring bands in the $\mathrm{OH}$ stretching vibrational region, in the range from $\sim 3750$ to $3100 \mathrm{~cm}^{-1}$. For instance, Matsyuk and Langer [2004] designated 70 different bands present in varying combinations in a suite of olivines from kimberlitic xenoliths from the Siberian shield. Most of the IR bands are sharp (small full-width at half maximum, FWHM) and exhibit strong polarization, most typically showing strongest absorption with the E-vector $(\mathbf{E})$ parallel to [100]. The greater variety of band positions in comparison to other nominally anhydrous minerals complicates attempts to uniquely assign bands to specific $\mathrm{OH}$ defects within the olivine crystal structure [Libowitzky and Beran, 1995]. Consequently, disagreement remains about band assignments and modes of hydrogen incorporation in olivine. A further complication is that some natural olivines contain inclusions of water or hydrous solid phases such as serpentine, talc, and humiteseries minerals (for a recent discussion of the nomenclature of humite-series minerals, see Matsyuk and Langer [2004]). As these inclusions often can only be observed at the nm-scale using electron microscopy, some of the $\mathrm{OH}$ in olivine may be falsely interpreted as being integral to its structure.

Extensive tables of band positions and FWHM in olivine can be found in several papers [Miller et al., 1987; Libowitzky and Beran, 1995; Kurosawa et al., 1997; Khisina et al., 2001; Matsyuk and Langer, 2004]. In an attempt to simplify the situation, we adopt and modify the simple scheme of Bai and Kohlstedt [1993], who divided the bands in their experimentally annealed olivines into two groups: Group I, including bands from 3450 to $3650 \mathrm{~cm}^{-1}$, and 
TABLE 2. Average electron microprobe analyses of selected olivine crystals and Ti-clinohumite in GRR1784a

\begin{tabular}{|c|c|c|c|c|c|c|c|c|}
\hline Sample no. & GRR999a & GRR1007 & GRR1006 & GRR1629 & GRR1784e & GRR1390 & GRR1784a & $\begin{array}{c}\text { GRR1784A } \\
\text { - Ti-Chu } \\
\text { inclusion }\end{array}$ \\
\hline Locality & Zabargad & Vesuvius & Monastery & Buell Park & Buell Park & Buell Park & Buell Park & Buell Park \\
\hline No. analyses ${ }^{\mathrm{a}}$ & $3 / 3$ & $3 / 3$ & $2 / 3$ & $3 / 3$ & $3 / 3$ & $3 / 6$ & $3 / 4$ & $2 / 0$ \\
\hline $\mathrm{SiO}_{2}$ & 40.63 & 40.09 & 40.54 & 40.74 & 40.89 & 40.40 & 40.84 & 36.17 \\
\hline $\mathrm{TiO}_{2}^{2}$ & 0.004 & 0.009 & 0.004 & n.d. & 0.005 & 0.058 & 0.012 & 5.20 \\
\hline $\mathrm{Al}_{2} \mathrm{O}_{3}$ & n.d. & 0.013 & n.d. & n.d. & n.d. & n.d. & n.d. & n.d. \\
\hline $\mathrm{FeO}$ & 9.38 & 12.41 & 7.72 & 8.27 & 7.63 & 9.08 & 7.86 & 7.88 \\
\hline $\mathrm{MnO}$ & 0.125 & 0.219 & 0.101 & 0.113 & 0.109 & 0.143 & 0.094 & 0.10 \\
\hline $\mathrm{MgO}$ & 50.01 & 46.55 & 50.85 & 50.83 & 50.42 & 49.91 & 50.81 & 48.56 \\
\hline $\mathrm{CaO}$ & 0.009 & 0.310 & n.d. & n.d. & n.d. & n.d. & n.d. & n.d. \\
\hline $\mathrm{NiO}$ & 0.315 & 0.179 & 0.354 & 0.404 & 0.389 & 0.367 & 0.305 & 0.30 \\
\hline $\mathrm{Na}_{2} \mathrm{O}$ & n.d. & n.d. & n.d. & n.d. & n.d. & n.d. & n.d. & n.d. \\
\hline $\mathrm{Cr}_{2} \mathrm{O}_{3}$ & n.d. & 0.012 & n.d. & n.d. & n.d. & 0.009 & n.d. & 0.05 \\
\hline Total & 100.48 & 99.81 & 99.59 & 100.37 & 99.46 & 99.99 & 99.93 & 98.28 \\
\hline $\mathrm{Mg} \#^{\mathrm{b}}$ & 90.5 & 87.0 & 92.2 & 91.6 & 92.2 & 90.7 & 92.0 & 91.7 \\
\hline
\end{tabular}

Notes:

all concentrations expressed in weight percent

n.d. = below detection limit (typically 10-30 ppm by weight)

aNumber of major/trace analyses averaged for table.

${ }^{b} \mathrm{Mg} \#=100 \times$ molar $\mathrm{Mg} /(\mathrm{Mg}+\mathrm{Fe})$

Group II, over the range from 3200 to $3450 \mathrm{~cm}^{-1}$. In addition, we distinguish a subset of Group I bands, hereafter referred to as "Group Ia", which comprises two strong bands near 3573 and $3525 \mathrm{~cm}^{-1}$ with shoulders at 3563 and $3541 \mathrm{~cm}^{-1}$. Other bands that have been conclusively linked to the presence of extrinsic hydrous phases [Kitamura et al., 1987; Miller et al., 1987; Matsyuk and Langer, 2004] are also noted below and in Table 1 .

The delineation of the band groups is illustrated in Figure 1, where we show that the classification can be applied not only to experimental samples [Zhao et al., 2004; Mosenfelder et al., 2006] but also to natural olivines. Further examples of the distinction between $I$ and Ia bands can be seen in Figures 2 and 3. Figure 2 illustrates spectra from a suite of olivines from the Buell Park and Green Knobs diatremes in Arizona. Figure 3 shows spectra from olivines that come from the Western Gneiss Region in Norway. Group I bands have been suggested to be a feature indicative of high pressures [Mosenfelder et al., 2006]. Group Ia bands, which are strongly correlated in peak height [Matsyuk and Langer, 2004], have been associated with humite-like defects [Kitamura et al., 1987; Miller et al., 1987], but the exact nature of the defects may vary between samples or even within a single sample. The significance of Group II bands is controversial [Matveev et al., 2001; Lemaire et al., 2004] and may be related either to varying silica activity or oxygen fugacity. These issues are discussed in the next section.

\section{MECHANISMS OF HYDROGEN INCORPORATION IN OLIVINE}

Incorporation of hydrogen in olivine can occur via the following classes of mechanisms: 1 ) as point defects; 2 ) in planar defects, comprised of either a separate hydrous phase or an ordered array of point defects; 3 ) via inclusions of hydrous minerals; and 4) as inclusions of fluid $\mathrm{H}_{2} \mathrm{O}$. Evidence to support these mechanisms comes primarily from IR spectra and TEM studies. Below we review each of these mechanisms, using new observations from the present study as well as literature data.

\subsection{Point Defects}

Point defects have long been linked to hydrogen incorporation in olivine [Beran, 1969; Beran and Putnis, 1983; Bai and Kohlstedt, 1992; 1993]. Possible defects that can balance the excess charge attending incorporation of hydrogen bonded to oxygen include coupled substitution with non-divalent impurity cations (e.g., $\mathrm{Al}^{3+}$ and $\mathrm{Cr}^{3+}$ in tetrahedral sites, or $\mathrm{Na}^{+}$and $\mathrm{Li}^{+}$in octahedral sites), metal (Fe and $\mathrm{Mg}$ ) vacancies, $\mathrm{Si}$ vacancies, ferric iron $\left(\mathrm{Fe}^{3+}\right)$ in tetrahedral sites, and oxygen interstitials. $\mathrm{OH}$ associated with line defects has also been suggested [Beran and Putnis, 1983], although there is no direct evidence for this mechanism.

The question of which - if any - types of defects dominate under different conditions is still under debate and it is not 
straightforward to assign IR bands uniquely to specific point defects based on dipole directions and wavenumber positions. For instance, Libowitzky and Beran [1995] thoroughly analyzed the IR spectra of a nearly pure Mg-end member forsterite crystal and could not assign all bands uniquely to either $\mathrm{Mg}$ or Si vacancies. Attempts to correlate trace element concentrations in olivine with hydrogen content have met with mixed success. Coupled substitution of hydrogen and boron has been clearly demonstrated in some olivines [Sykes et al., 1994; Kent and Rossman, 2002], but this element is unlikely to be present at high levels throughout the mantle. Kurosawa et al. [1997] showed a positive correlation

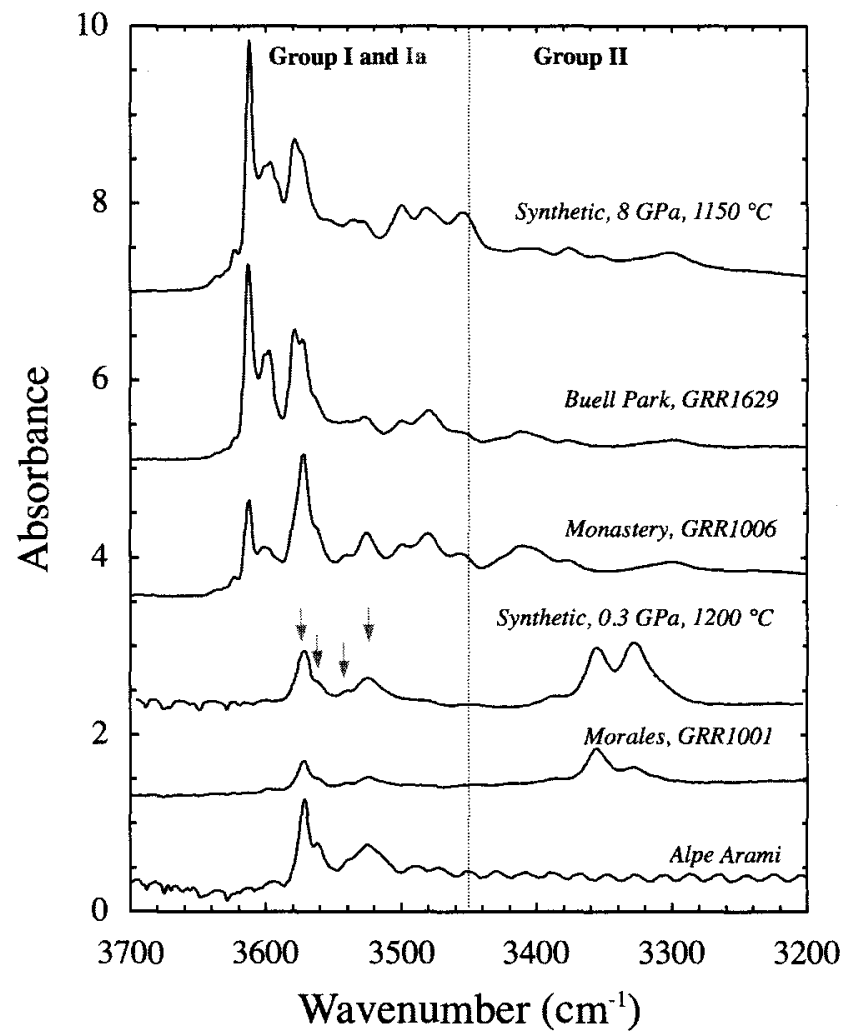

Figure 1. Comparison between Group I, Ia, and II IR bands, illustrated in both natural and experimental samples. The line divides Group II bands from Groups I and Ia, and the grey arrows point to the four Group Ia bands. All spectra normalized to $1 \mathrm{~cm}$ with the exception of the experimental sample [Mosenfelder et al., 2006] from $8 \mathrm{GPa}$ and $1150{ }^{\circ} \mathrm{C}$, normalized to $0.5 \mathrm{~mm}$. Spectra in this and other figures are offset in absorbance arbitrarily for the sake of clarity and comparison. All spectra polarized with $\mathbf{E} \|[100]$ except for the spectrum taken from Zhao et al. [2004] of an experimental sample annealed at $0.3 \mathrm{GPa}$ and $1200^{\circ} \mathrm{C}$, which is nominally unpolarized with the incident beam parallel to [010]. Polarized spectra with E $\|$ [010] and [001] for GRR1629 and the 8 GPa synthetic sample published in Mosenfelder et al. [2006]. Natural samples from localities discussed in Table 1 and in the text.

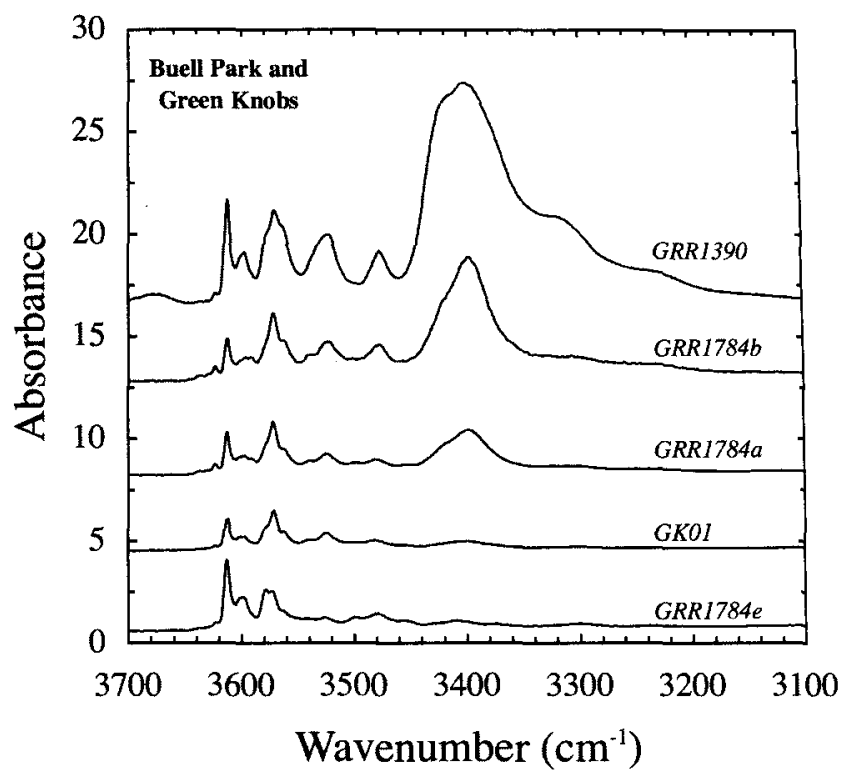

Figure 2. IR spectra of olivines from Buell Park and Green Knobs, polarized with $\mathbf{E} \|[100]$. The sample numbers are listed directly above each spectrum. Note gradation from spectrum dominated by Group I bands (GRR1784e) to spectra showing Group Ia bands and bands attributed to Ti-clinohumite.

of trivalent cations $\left(\mathrm{Al}^{3+}, \mathrm{Cr}^{3+}\right)$ with monovalent cations $\left(\mathrm{H}^{+}, \mathrm{Li}^{+}, \mathrm{Na}^{+}\right)$in a suite of olivines from garnet peridotites, but a more recent study [Bell et al., 2004] failed to reveal any such correlation. Even more recently, Hauri et al. [in press] obtained ion microprobe analyses on experimental samples showing both a rough equality between molar $\mathrm{H}$ and $\mathrm{Al}$ contents as well as a correlation between $\mathrm{Al}$ content in olivine and partitioning of hydrogen between olivine and melt. They used this evidence to argue for a prominent role of $\mathrm{Al}$ in hydrogen incorporation in olivine, but the correlation shows considerable scatter and application to natural samples is uncertain.

A prominent role for either oxygen interstitials or metal vacancies has been argued on the basis of thermodynamics, point defect studies under anhydrous conditions, and IR data on experimental samples [Bai and Kohlstedt, 1993; Kohlstedt et al., 1996; Kohlstedt and Mackwell, 1998; Zhao et al., 2004]. On the other hand, the ab initio calculations of Brodholt and Refson [2000] suggest that the concentration of silicon vacancies is enhanced under hydrous conditions. In this case, silica activity would be expected to play an important role in hydrogen incorporation, as argued by Matveev et al. [2001], who ascribed Group I bands to Si vacancies formed under conditions of low silica activity (in equilibrium with $\mathrm{MgO}$ ) and Group II bands to metal vacancies formed under higher silica activity conditions (in equilibrium with orthopyroxene). This conflicts with the previous experi- 


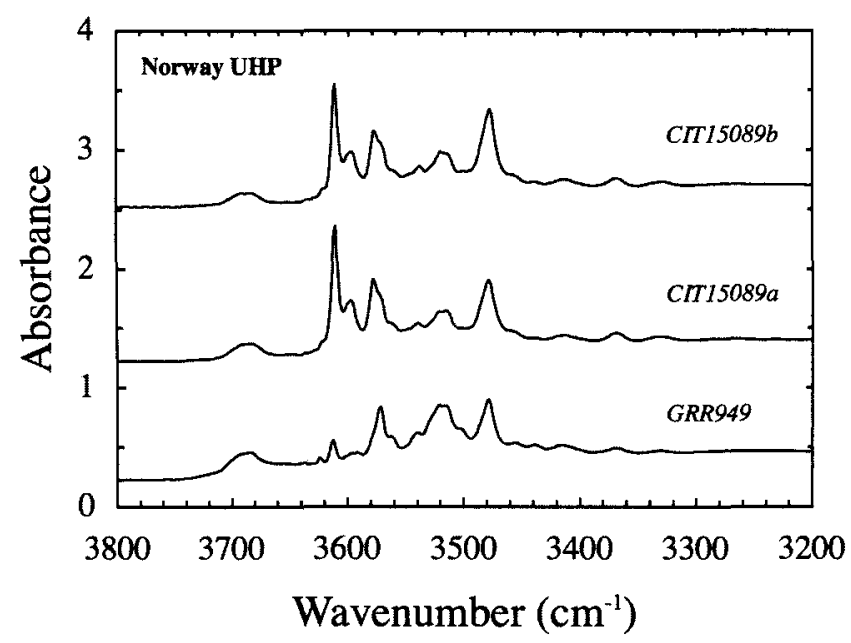

Figure 3. IR spectra of olivines from Almklovdalen, in the UHP province of the Western Gneiss Region, Norway. All spectra normalized to $1 \mathrm{~cm}$ and polarized with $\mathbf{E} \|[$ [100]. The previously published [Miller et al., 1987] spectrum for sample GRR949 predominantly shows Group Ia bands, but the other two crystals predominantly show Group I bands. The broad band at $3685 \mathrm{~cm}^{-1}$ is assigned to serpentine.

mental results of Bai and Kohlstedt [1993], who showed no evidence for a significant effect of silica activity on incorporation mechanism. Moreover, it implies that the vast majority of natural olivines, which are dominated by Group I or Ia bands (Figures 1-3; [Miller et al., 1987]), were equilibrated at low silica activity. This conclusion is problematic as most of these olivines come from orthopyroxene-bearing peridotite sources.

A possible resolution to this problem, as argued by Mosenfelder et al. [2006] [see also Berry et al., 2005], is that the Group II bands are related to elevated oxygen fugacity rather than differences in silica activity. This conclusion is consistent with the faster increase in peak heights of Group II bands (compared to Group I) with increasing oxygen fugacity documented in the original study of Bai and Kohlstedt [1993], and with the oxygen buffer used in the experiments of Matveev et al. [2001]. However, this does not explain another set of low-wavenumber bands seen in two more recent experimental studies. These bands, at 3160 and 3230 $\mathrm{cm}^{-1}$, are present in both Fe-free [Demouchy and Mackwell, 2003; Lemaire et al., 2004] and Fe-bearing [Berry et al., 2005] olivines synthesized under high-silica activity conditions at pressures below $2 \mathrm{GPa}$. Although Berry et al. [2005] only presented unpolarized spectra, the bands observed by Demouchy and Mackwell [2003] and Lemaire et al. [2004] are broad and strongly polarized with the greatest absorption \| [001], unlike most other bands in olivine. The band at $3160 \mathrm{~cm}^{-1}$ has not been seen in any natural olivines, to our knowledge, but the band at $3230 \mathrm{~cm}^{-1}$ may correspond to a band with the same polarization seen in olivines from Buell Park (Figure 2), Zabargad Island, Egypt, and Vesuvius, Italy Figure 4). This band is correlated with the presence of a band near $3400 \mathrm{~cm}^{-1}$ in natural samples (Figures 2 and 4 ) and in some experimental samples [Lemaire et al., 2004, Figure 6]. Bands at nearly identical wavenumbers are also present in the spectra of Ti-clinohumite [Matsyuk and Langer, 2004]. Based on this correspondence, these bands may represent the presence of defects or inclusions related to Ti-clinohumite, as discussed further below, even though the $3230 \mathrm{~cm}^{-1}$ band has also been attributed to OH defects [Kitamura et al., 1987] or even molecular water [Matsyuk and Langer, 2004].

\subsection{Planar Defects}

4.2.1. Clinohumite Lamellae. OH-bearing, planar defects (stacking faults) in olivine were described by Kitamura et al. [1987], who studied sample GRR1390 (from Buell Park, Arizona) using TEM. The defects are aligned parallel to (001), (021), and (0-21) (Figure 5). Similar defects along (001) have been documented by Drury [1991], Sykes et al. [1994], and Risold et al. [2001]. They have also been reproduced in high-pressure experiments [Wirth et al., 2001].

Based on the displacement vector $(\mathbf{R}=1 / 4<011>)$ of the defects, Kitamura et al. [1987] determined that their structure was consistent with layers of Ti-clinohumite. This conclusion is also consistent with IR spectra of the sample, which show strong Group Ia bands at 3571 and $3524 \mathrm{~cm}^{-1}$, as well as a very strong band at $3402 \mathrm{~cm}^{-1}$ with shoulders at 3422,3319 , and $3230 \mathrm{~cm}^{-1}$. All of these bands can be ascribed to Ti-clinohumite [Miller et al., 1987; Matsyuk and Langer, 2004]. Furthermore, the orange to orange-yellow pleochroism of GRR1390, unusual for olivine, is similar to that of Ti-clinohumite. We re-examined this sample with TEM and confirmed the structure and displacement vector of the defects using high-resolution imaging (Figure 5a-c). Moreover, qualitative EDS analyses of the stacking faults reveal high Ti concentrations, and EMP analyses of the bulk sample (Table 2) show unusually high Ti content for olivine ( $580 \mathrm{ppm} \mathrm{TiO}_{2}$ by weight), consistent with the original attribution of the defects as Ti-clinohumite layers.

We have also detected planar defects in GRR1784a, another olivine crystal from Buell Park that shows IR bands corresponding to the presence of Ti-clinohumite (Figure 2). The density of planar defects in GRR1784a is lower, the defect segments are generally shorter, and there are no (021) and (0-21) segments; the sample also contains a significantly higher density of dislocations and subgrain boundaries. GRR1784a lacks the unusual pleochroism of GRR1390 (it is a "normal" green color) and EMP analyses reveal a lower Ti 
content ( $117 \mathrm{ppm}$ wt $\mathrm{TiO}_{2}$ ), although significantly above the detection limit ( $30 \mathrm{ppm})$. Furthermore, this sample contains optically detectable inclusions of Ti-clinohumite (Figure $5 e-f$ ), discussed in more detail in section 4.3. Figure 2 also shows another Buell Park olivine (GRR1784b) exhibiting the band at $3402 \mathrm{~cm}^{-1}$, with intensity intermediate between GRR1784a and GRR1390; this olivine has similar pleochroism to GRR1390 and presumably contains planar defects, but we have not examined it using TEM or EMPA.

Risold et al. [2001] showed that the planar defects in olivine from the Alpe Arami garnet peridotite are linked directly to ilmenite $\left((\mathrm{Mg}, \mathrm{Fe}) \mathrm{TiO}_{3}\right)$ inclusions, which have nucleated on the defects. We have collected IR spectra from several grains of olivine containing ilmenite inclusions. Fig. 1 shows the $\mathbf{E} \|[100]$ spectrum of Alpe Arami olivine, showing only type Ia bands without the band at $3402 \mathrm{~cm}^{-1}$. Predominance of the latter band appears to be diagnostic of Ti-bearing humite-series minerals [Miller et al., 1987]; although Matsyuk and Langer [2004] presented IR data from humite-series minerals nominally lacking $\mathrm{Ti}$ that also show this band, they did not present microprobe data for these samples. Moreover, synthetic, Ti-free clinohumite exhibits no band at this wavenumber [ $\mathrm{Liu}$ et al., 2003]. Therefore, the IR spectrum of the Alpe Arami olivine is consistent with the hypothesis of Risold et al. [2001] that the planar defects were originally Ti-clinohumite but have lost Ti via diffusion during precipitation of the ilmenite rods in the sample. This explanation obviates the need for very high pressures (7 GPa or higher) advocated by Dobrzhinetskaya et al. [1996]

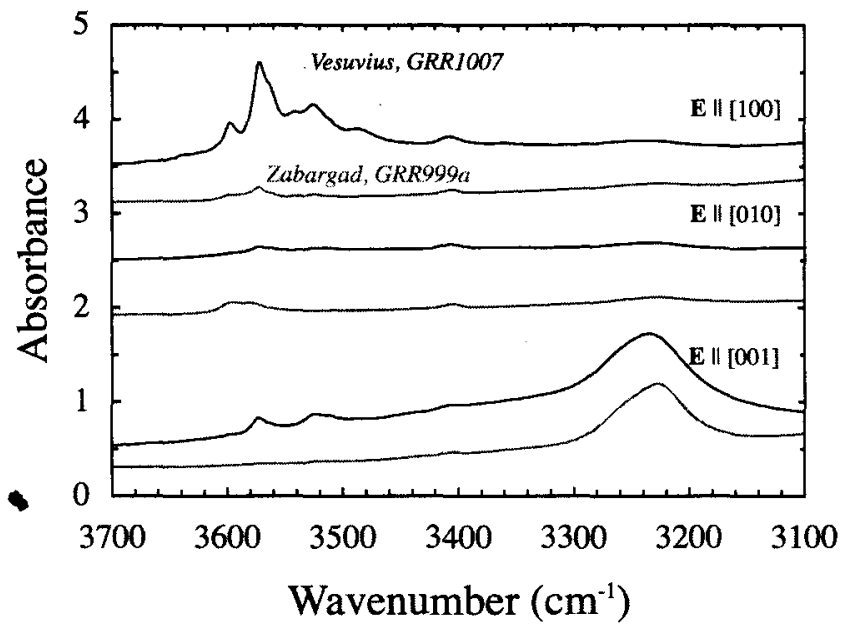

Figure 4. IR spectra of olivines from Vesuvius, Italy (black) and Zabargad Island, Egypt (grey). All spectra normalized to $1 \mathrm{~cm}$. The top two spectra are polarized with $\mathbf{E} \|[100]$, the middle two with $\mathbf{E} \|$ [010], and the bottom two with $\mathbf{E} \|$ [001]. The band at 3404 $\mathrm{cm}^{-1}$ is weakly polarized, but the band near $3230 \mathrm{~cm}^{-1}$ is strongly polarized, showing greatest absorption with $\mathbf{E} \|$ [001]. [see also Bozhilov et al., 2003] to explain the existence of the ilmenite rods, because Ti solubility in olivine has been shown to be a strong function not of pressure but of temperature [Hermann et al., 2005].

4.2.2. Hydrous-modified Olivine. Khisina et al. [2001] and Khisina and Wirth [2002] documented a different type of OH-bearing planar defect in an olivine crystal in a kimberlitic xenolith from the Siberian Platform. The planar defects in this sample are grouped together in lamellae, wider than the clinohumite defects discussed above. EDS analyses of the lamellae show a deficiency of $\mathrm{Mg}$ and Fe relative to the surrounding olivine. In addition to the lamellae, discrete, $\mathrm{nm}$-sized inclusions of the same phase are present. Khisina and Wirth [2002] interpreted the lamellae to be ordered arrays of $\mathrm{M}$-site ( $\mathrm{Mg}$ and $\mathrm{Fe}$ ) vacancies in olivine and called this new phase "hydrous olivine". A similar structural model was devised by Kudoh [2002], who called the theoretical phase "hydrous-modified olivine." Although the structure of this phase is similar to clinohumite, it is chemically distinct in that $\mathrm{Mg} / \mathrm{Si}<2$, whereas the humite-series minerals have $\mathrm{Mg} / \mathrm{Si}>2$. Intriguingly, the IR spectra of the sample studied by Khisina et al. [2001] show a predominance of the same Group Ia bands seen in many other olivines, as well as in samples GRR1390 and GRR1784a, which contain distinct clinohumite layers. Thus, it is apparently not possible to distinguish between defects that are $\mathrm{Mg} / \mathrm{Fe}$-deficient and those that are Si-deficient, using IR spectroscopy alone.

\subsection{Hydrous Mineral Inclusions}

Effective "incorporation" of hydrogen in olivine via inclusion of, or intimate intergrowth with, hydrous minerals has also been long recognized. For instance, McGetchin et al. [1970] described intergrowths of Ti-clinohumite and olivine (as well as Ti-clinohumite inclusions in garnet) and suggested the importance of Ti-clinohumite as a carrier for water in the mantle, long before the importance of nominally anhydrous minerals was broadly recognized. Based on IR spectra, Miller et al. [1987] established the presence of other hydrous inclusions in some olivines that were not distinguishable using optical methods. These include serpentine, exhibiting a complex multiplet of bands around $3680 \mathrm{~cm}^{-1}$, and talc, distinguished by a sharper band at $3678 \mathrm{~cm}^{-1}$ together with a much smaller band at $3662 \mathrm{~cm}^{-1}$. The possible presence of humite-series minerals was also discussed at length by Miller et al. [1987], but the correspondence of band positions was not found to be as precise as for serpentine and talc. More recently, Khisina et al. [2001] documented $\mathrm{nm}$-scale inclusions of talc, serpentine and $10-\AA$ phase in olivines using TEM, and Matsyuk and Langer [2004] presented evidence from IR spectra for sub-microscopic inclu- 

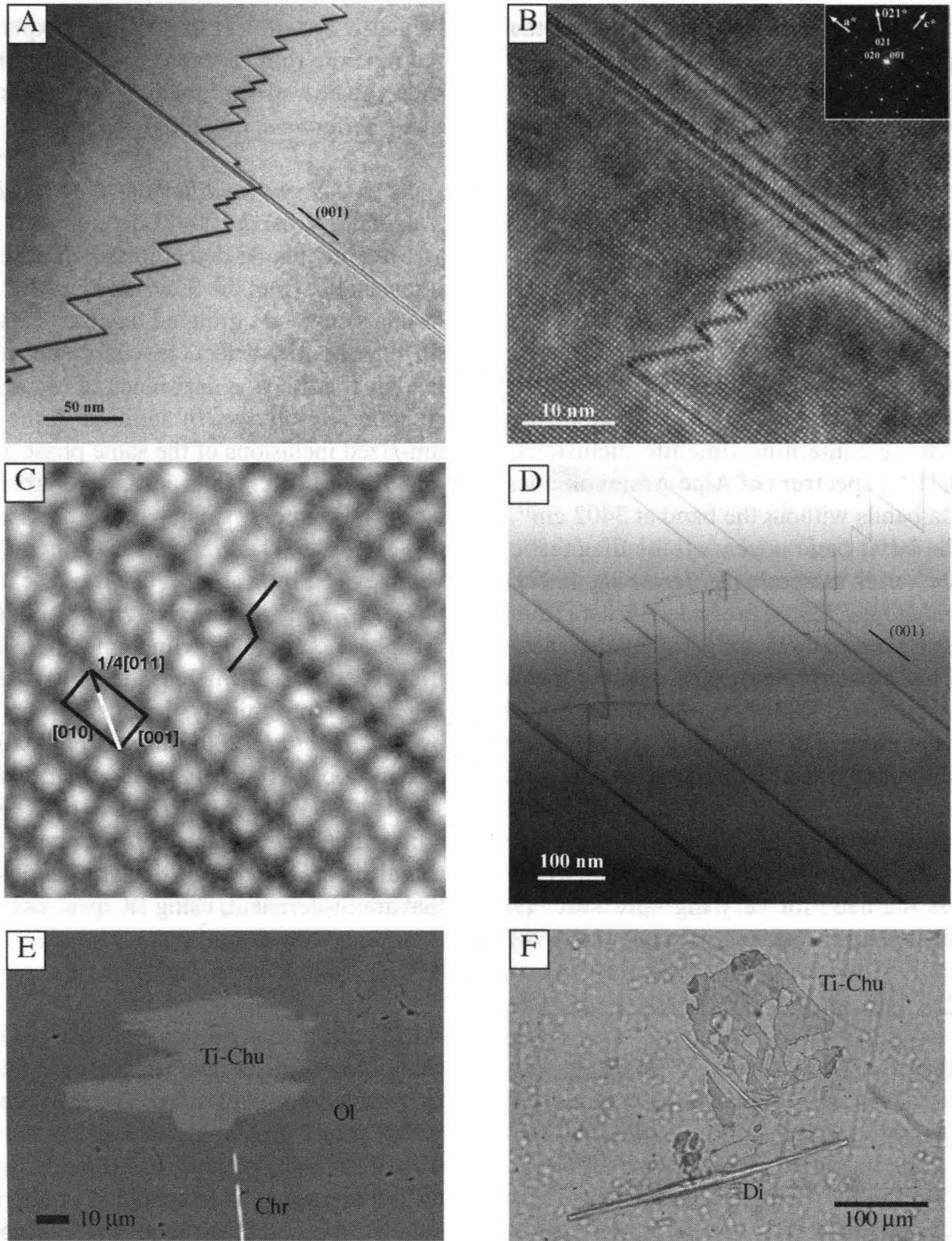

Figure 5. Inclusions of Ti-clinohumite (Ti-Chu) from the nanometer- to micrometer-scale in olivines from Buell Park, Arizona. (a) Bright-field TEM image of Ti-Chu defects in sample GRR1390 taken with diffraction to $g=004$. The image shows two long straight defects on (001) and a zigzag defect that consists of short (001) and (021) segments. (b) High-resolution TEM (HRTEM) image of the same set of planar defects as in (a), taken down the [100] zone axis. Ti-Chu layers parallel to (001) are present as are defects along (021). The inset selected-area electron diffraction pattern is the [100] zone axis. (c) Enlargement of HRTEM image in (b) demonstrating that the displacement of the (001) and (020) lattice fringes is consistent with a displacement vector $\mathbf{R}=1 / 4<011>$. The displacement is illustrated by the zig-zag line in the middle of the image. (d) Bright-field TEM image of Ti-Chu defects in GRR1390 showing the interaction between planar (001) defects and complex zig-zag defects consisting of (001), (021) and (0-21) segments. Note that double (001) defects terminate into (021) $+(0-21)$ pairs. Image taken with diffraction to $g=004$. (e) BSE image of a Ti-Chu inclusion in sample GRR1784A. The bright, needle-like phase is chromite (Chr). An EMPA analysis of the Ti-Chu inclusion is shown in Table 2. (f) Optical photo-micrograph in plane-polarized light of a Ti-Chu inclusion in GRR1784A associated with diopside (Di) needles. The inclusions form as flattened plates in the (100) plane of the crystal. Similar Ti-Chu inclusions were also identified in GRR1006. 
sions of serpentine, talc, amphibole and hydrous wadsleyite (one of the high-pressure forms of olivine). We consider the attribution of the latter two phases to be highly speculative; the IR bands of amphiboles overlap those of serpentine, while the bands attributed to hydrous wadsleyite (at $3327 \mathrm{~cm}^{-1}$ and 3357 $\mathrm{cm}^{-1}$ ) are identical to two of the Group II bands, which are present in low-pressure olivines, show strong anisotropy, and probably are related to elevated oxygen fugacity as discussed in section 4.1 above.

Inclusions of talc and serpentine most likely represent secondary alteration of olivines, but some humite-series minerals may be stable at the high pressure and temperature conditions from which mantle xenoliths are extracted [Ulmer and Trommsdorff, 1999]. In addition to the planar defects described above, we have identified micrometer-scale inclusions of Ti-clinohumite (Figure $5 \mathrm{e}-\mathrm{f}$ ) in samples from Buell Park (GRR1784a and other crystals not yet prepared for IR or EMP analysis) and in a crystal from the Monastery kimberlite in South Africa (GRR1006). These orange-colored inclusions comprise very thin platelets confined to the (100) planes of the green-colored olivines. They have been positively identified by Raman spectroscopy as well as electron microprobe analysis (Table 2). In sample GRR1784a, they are associated with other oriented crystals identified by EDS as diopside and chromite (Figure $5 \mathrm{e}-\mathrm{f}$ ). This association suggests that they form by exsolution during cooling from higher temperatures to the conditions from which the xenoliths were extracted; the solubility of trace elements such as $\mathrm{Ti}, \mathrm{Al}, \mathrm{Ca}$ and $\mathrm{Cr}$ in olivine is expected to increase with temperature [e.g., Hermann et al., 2005].

Although inclusions of Ti-clinohumite were predicted [Miller et al., 1987; Libowitzky and Beran, 1995] to be present in olivines from Zabargad Island, Egypt and Vesuvius, Italy (Figure 4), we have not found any optically detectable inclusions in these samples (more than 20 crystals from Zabargad were examined for this purpose). We also studied Zabargad olivine using TEM [cf. Beran and Putnis, 1983] and did not find planar defects of the type discussed above. Furthermore, we did not observe any nanometer-scale precipitates of Ticlinohumite such as those identified by Wirth et al. [2001] in an experimental sample. We tentatively suggest that the bands in these samples near $3400 \mathrm{~cm}^{-1}$ and $3230 \mathrm{~cm}^{-1}$ represent point defects related to humite, but more work is needed to model the nature of these defects; another possibility is that lamellae or inclusions of Ti-clinohumite are present but at such low density that we were unable to detect them.

\subsection{Fluid-Inclusion $\mathrm{H}_{2} \mathrm{O}$}

Many minerals exhibit a broad band of absorption that is centered at $3420 \mathrm{~cm}^{-1}$ and lacks polarization. This band may underlie sharp bands that are polarized [Miller et al., 1987; Bell et al., 2004; Rossman et al., in preparation]. Although this band has been associated with the presence of fluid inclusions, the inclusions may not be optically visible. Miller et al. [1987] documented such a feature in a sample from Kimberley, South Africa and suggested that it reflected the presence of submicroscopic fluid inclusions so small that ice could not form during cooling (to $77 \mathrm{~K}$ ) of the olivine. Indeed, abundant nanometer-scale pores in this specimen have recently been imaged using high-resolution scanning electron microscopy [Rossman et al., in preparation]. Although other broad bands at lower energies (between 3175 and $3260 \mathrm{~cm}^{-1}$ ) have also been tentatively assigned to molecular water with "relatively strong bonds to the matrix" [Matsyuk and Langer, 2004], there is no direct evidence to support this suggestion. Moreover, the band near $3230 \mathrm{~cm}^{-1}$ with strong polarization $\|[001]$ may be associated with a humite-type defect as discussed above.

The presence of a large broadband component that is not associated with visible fluid inclusion arrays or fractures appears to be a phenomenon restricted to olivines from very high-pressure xenoliths [Miller et al., 1987; Bell et al., 2004]. Nanometer-scale features such as those documented by Rossman et al. [in preparation] may represent water exsolved from the structure of the olivine during rapid decompression and cooling. Thus, while providing an intriguing signature, it is not clear whether these inclusions represent a valid mechanism for incorporating hydrogen in olivine in situ in the mantle.

\section{DISCUSSION}

\subsection{Effect of Pressure on Hydrogen Incorporation in Olivine}

Bai and Kohlstedt [1993] and Kohlstedt et al. [1996] established the systematic, dramatic increase of water storage capacity in olivine with increasing pressure, and the recent experiments of Mosenfelder et al. [2006], using an updated IR calibration [Bell et al., 2003], confirm these results and indicate that the storage capacity of olivine is even higher than previously thought [cf. Smyth et al., 2005]. Although the applicability of some of these experiments to the mantle has been questioned [Matveev et al., 2001; Lemaire et al., 2004; Berry et al., 2005; Matveev et al., 2005], our comparison of IR spectra from synthetic and natural samples (Figure 1) shows that whatever mechanism is responsible for hydrogen incorporation in experiments from about $2-13 \mathrm{GPa}$ is also operative in some natural samples. Mosenfelder et al. [2006] suggested that there may be a transition in mecha- 
nisms between low pressures, where a humite-type defect represented by Group Ia bands dominates, and high pressures, where a different defect associated with Group I bands (particularly the bands at 3613,3598 , and $3579 \mathrm{~cm}^{-1}$, but also, in some samples, a triplet at 3502,3483 and $3456 \mathrm{~cm}^{-1}$ ) dominates. Berry et al. [2005] also speculated on a change in hydrogen incorporation mechanism at high pressures, suggesting that the Group I bands may reflect the presence of Ti-free, "OH-clinohumite-like defects". This assignment is problematic based on comparison between the relatively simple IR spectra of $\mathrm{OH}$-clinohumite, containing only three bands [Liu et al., 2003], and the more complicated pattern of Group I bands noted above. Nevertheless, TEM studies of experimental samples are warranted in order to investigate the possibility that layers or inclusions of $\mathrm{OH}$-clinohumite are present.

The natural olivines represented by the upper three spectra in Figure 1 and the spectra in Figures 2 and 3 all originally come from high-pressure environments. The exact pressure and temperature conditions of formation for the xenolithic olivines are difficult to constrain because they were collected as discrete grains without accompanying phases. However, for the Buell Park olivines, derivation from the garnet peridotite stability field is suggested based on association with pyropic garnet and $\mathrm{Cr}$-diopside and the high $\mathrm{Mg}$-number $\left(\sim \mathrm{Fo}_{92}\right.$, Table 2$)$ of the olivines compared to the Mg-number of olivines in spinel-peridotite xenoliths from the same locality [Smith and Levy, 1976]. Even higher pressures and temperatures have been suggested for xenoliths from the Monastery kimberlite [Bell et al., 2004], although GRR1006 presumably comes from a different xenolithic suite than the olivines studied by Bell et al. [2004]. We note that the olivines in that study, which are among the most $\mathrm{OH}$-rich natural olivines ever measured, are dominated by Group Ia IR bands, which contradicts the hypothesis of Mosenfelder et al. [2006]. However, these olivines are also substantially more Fe-rich $\left(\mathrm{Fo}_{80}-\mathrm{Fo}_{82}\right.$, Table 5 in Bell et al. [2004]) than the olivines $\left(\mathrm{Fo}_{92}\right.$, Table 2$)$ that are dominated by Group I bands, and the presence of Fe may stabilize whatever defect is represented by the Group Ia bands, as suggested by the experimental data of Zhao et al. [2004]. The OH-rich sample from Vesuvius, Italy (Figure 4) also exhibits strong Group Ia bands and is relatively $\mathrm{Fe}$-rich $\left(\mathrm{Fo}_{87}\right.$, Table 2$)$.

The olivine crystals from Norway come from a garnetperidotite body (Almklovdalen) in the ultrahigh-pressure province of the Western Gneiss Region. The IR spectrum of sample GRR949, originally published by Miller et al. [1987], shows very weak Group I bands and stronger Group Ia bands, but the other two olivines exhibit distinctly different IR spectra (Figure 3), with strong Group I bands at 3613, 3598 and $3579 \mathrm{~cm}^{-1}$. These crystals may have experienced peak pressures of $3.8 \mathrm{GPa}$ [Medaris, 1999] or even higher [van Roermund et al., 2000]. However, they obviously had a more protracted history of exhumation to the surface than the xenoliths discussed above and have likely been affected by fluid infiltration events at lower pressures [Kostenko et al., 2002], reflected by the ubiquitous presence of serpentine in these samples. Because the diffusion of hydrogen in olivine is known to be rapid [Kohlstedt and Mackwell, 1998; Demouchy and Mackwell, 2003], at least on the several million-year timescale it must have taken for exhumation of these rocks, the proposed survival of a "high-pressure $\mathrm{OH}$ signature" is therefore surprising. Unfortunately the samples, received as donations from gem dealers, do not have a properly documented geologic context. A more thorough study of $\mathrm{OH}$ in olivines from ultra-high pressure garnet-peridotites could yield further information with respect to hydrogen incorporation mechanisms at high pressure.

\subsection{Ti in Olivine and the Importance of Humite-Type Defects}

The existence of planar defects and inclusions of Ti-clinohumite in olivine described above suggest a potentially important role for $\mathrm{Ti}$ in incorporation of hydrogen in olivine. We note that although these defects and inclusions have been identified in olivines from two different, far-apart localities (Buell Park, Arizona and Monastery Mine, South Africa), the ubiquity of such a phenomenon in the mantle is far from certain. For instance, Matsyuk and Langer [2004] studied a much larger suite of olivines in kimberlitic xenoliths from the Siberian shield and none of their samples show the band at $3402 \mathrm{~cm}^{-1}$ characteristic of Ti-clinohumite. The Ti-clinohumite defects and inclusions appear to reflect exsolution from olivines containing structural $\mathrm{Ti}$ and $\mathrm{H}$; exsolution of other trace elements $(\mathrm{Cr}, \mathrm{Al}$, and $\mathrm{Ca})$ in these samples has also clearly taken place as reflected by the presence of associated chromite and diopside inclusions (Figure 5). For the Buell Park samples such a process is consistent with petrological studies that document protracted cooling of the xenoliths prior to extraction from the mantle source [Smith and Levy, 1976]. Ti, which is highly soluble in olivine at high temperatures according to the experimental data of Hermann et al. [2005], may have been introduced into the olivines by localized metasomatism at high temperatures; this would be consistent with the highly variable concentration of $\mathrm{Ti}$ and Ti-clinohumite defects in these samples (Figure 2 and Table 2). Note that the history of the Alpe Arami garnet lherzolite, containing similar planar defects in olivine, is quite different and probably reflects a multi-stage process such as that proposed by Hermann et al. [2005]. In this case the Ti-clinohumite, perhaps formed by an exsolution process analogous 
to that in the Buell Park samples, must have become unstable during a later metamorphic event as evidenced by breakdown of the defects to form ilmenite (plus olivine). This secondary event may reflect either prograde metamorphism [Hermann et al., 2005] or retrograde metamorphism at relatively high temperatures during rapid exhumation.

Berry et al. [2005] have suggested that a point defect associated with $\mathrm{Ti}$ is the most important defect site in the shallow upper mantle for incorporating hydrogen. The extremely high concentration of $\mathrm{OH}$ in olivines with presumably low Ti contents annealed at pressures up to $13 \mathrm{GPa}$ indicates that this is not the only important mechanism for incorporating hydrogen in olivine in deeper parts of the mantle. Moreover, the exact nature of the proposed "humite-type" point defects, as we have discussed throughout this paper, is uncertain. There may be more than one variety of "humite-type" defect, as suggested by differences in IR spectra of low-pressure olivines (compare Figures 1 and 4). A "hydrous-modified olivine" defect [Khisina and Wirth, 2002; Kudoh 2002] is one strong possibility that should be investigated further with combined IR and TEM studies of natural olivines.

Acknowledgments. Financial support for this work was provided by NSF grants OCE-0095294 and OCE-0241716 to PDA, EAR-0337816 to GRR, and EAR-0208419 to TGS. Several of the Buell Park samples came from the thesis collection repository of David Bell at Caltech. Doug Smith graciously provided samples, enlightening discussion and encouragement. Erik Hauri provided a preprint and went beyond the call of duty discussing it. We also thank Maarten Broekmans, Bradley Hacker, Stephen Mackwell, Gordon Medaris, Michael Roden, and Michael Terry for helpful discussions and information about localities. Chi Ma assisted with electron microprobe analyses. Thorough reviews by Andrew Berry, Steven Jacobsen and an anonymous reviewer helped us refine the manuscript. Finally, we once again thank all of the original donors who provided samples for the study of Miller et al. [1987], and especially Masao Kitamura, for continuing use of his samples from Buell Park.

\section{REFERENCES}

Armstrong, J. T., Quantitative analysis of silicate and oxide minerals, comparison of Monte Carlo, ZAF and $\phi(\rho z)$ procedures, in Microbeam analysis, edited by D. E. Newbury, pp. 239-246, San Francisco Press, San Francisco, CA, 1988.

Asimow, P. D., L. C. Stein, J. L. Mosenfelder, and G. R. Rossman, Quantitative polarized FTIR analysis of trace $\mathrm{OH}$ in populations of randomly oriented mineral grains, Am. Mineral., 91 , 278-284, 2006.

Bai, Q., and D. L. Kohlstedt, Substantial hydrogen solubility in olivine and implications for water storage in the mantle, Nature, 357, 672-674, 1992.
Bai, Q., and D. L. Kohlstedt, Effects of chemical environment on the solubility and incorporation mechanism for hydrogen in olivine, Phys. Chem. Miner., 19, 460-471, 1993.

Bell, D. R., and G. R. Rossman, Water in the Earth's mantle: the role of nominally anhydrous minerals, Science, 255, 1391-1397, 1992.

Bell, D. R., G. R. Rossman, J. Maldener, D. Endisch, and F. Rauch, Hydroxide in olivine: a quantitative determination of the absolute amount and calibration of the IR spectrum, J. Geophys. Res., 108, doi: 10.1029/2001JB000679, 2003.

Bell, D. R., G. R. Rossman, and R. O. Moore, Abundance and partitioning of $\mathrm{OH}$ in a high-pressure magmatic system: megacrysts from the Monastery Kimberlite, South Africa, J. Petrol., 45, 1539-1564, 2004.

Beran, A., Über (OH)-Gruppen in Olivin, Anzeiger der Osterreichischen Akademie der Wissenschaften, Mathematisch Naturwissenschaftliche Klasse, 73-74, 1969.

Beran, A., and A. Putnis, A model of the $\mathrm{OH}$ positions in olivine, derived from infrared-spectroscopic investigations, Phys. Chem. Miner., 9, 57-60, 1983.

Berry, A.J., J. Hermann, H. O'Neill, and G. J. Foran, Fingerprinting the water site in mantle olivine, Geology, 33(11), 869-872, 2005.

Bolfan-Casanova, N., Water in the Earth's mantle, Min. Mag., 69, 229-257, 2005.

Bozhilov, K. N., H. W. Green, and L. F. Dobrzhinetskaya, Quantitative 3D measurement of ilmenite abundance in Alpe Arami olivine by confocal microscopy: confirmation of high-pressure origin, Am. Mineral., 88, 596-603, 2003.

Brodholt, J. P., and K. Refson, An ab initio study of hydrogen in forsterite and a possible mechanism for hydrolytic weakening, J. Geophys. Res., 105, 18,977-918,982, 2000.

Demouchy, S.D., and S. Mackwell, Water diffusion in synthetic iron-free forsterite. Phys. Chem. Miner., 30, 486-494, 2003.

Demouchy, S.D., S.D. Jacobsen, F. Gaillard, and C.R. Stern, Rapid magma ascent recorded by water diffusion profiles in mantle olivine. Geology, 34, 429-432, 2006

Dobrzhinetskaya, L., H. W. Green II, and S. Wang, Alpe Arami: a peridotite massif from depths of more than 300 kilometers, Science, 271, 1841-1844, 1996.

Drury, M. R., Hydration-induced climb dissociation of dislocations in naturally deformed mantle olivine, Phys. Chem. Miner., 18 , 106-116, 1991.

Hauri, E.H., G.A. Gaetani, and T.H. Green, Partitioning of water during melting of the Earth's upper mantle at $\mathrm{H}_{2} \mathrm{O}$-undersaturated conditions, Earth Planet. Sci. Lett., in press, 2006.

Hermann, J., H. S. C. O'Neill, and A. Berry, Titanium solubility in olivine in the system $\mathrm{TiO}_{2}-\mathrm{MgO}-\mathrm{SiO}_{2}$ : no evidence for an ultradeep origin of Ti-bearing olivine, Contrib. Mineral. Petrol., 148, 746-760, 2005.

Hirschmann, M.M., A.C. Withers, and C. Aubaud (this volume), Petrologic structure of a hydrous $410 \mathrm{~km}$ discontinuity.

Ingrin, J., and H. Skogby, Hydrogen in nominally anhydrous uppermantle minerals: concentration levels and implications, Eur. J. Mineral., 12, 543-570, 2000. 
Kent, A. J. R., and G. R. Rossman, Hydrogen, lithium, and boron in mantle-derived olivine: the role of couple substitutions, $\mathrm{Am}$. Mineral., 87, 1432-1436, 2002.

Khisina, N. R., and R. Wirth, Hydrous olivine $\left(\mathrm{Mg}_{1-y} \mathrm{Fe}^{2+}{ }_{y}\right)_{2-\mathrm{x}} \mathrm{v}_{\mathrm{x}-}$ $\mathrm{SiO}_{4} \mathrm{H}_{2 x}$-a new DHMS phase of variable composition observed as nanometer-sized precipitations in mantle olivine, Phys. Chem. Miner., 29, 98-111, 2002.

Khisina, N. R., R. Wirth, M. Andrut, and A. V. Ukhanov , Extrinsic and intrinsic mode of hydrogen occurrence in natural olivines: FTIR and TEM investigation, Phys. Chem. Miner., 28, 291-301, 2001.

Kitamura, M., S. Kondoh, N. Morimoto, G. H. Miller, G. R. Rossman, and A. Putnis, Planar $\mathrm{OH}$-bearing defects in mantle olivine, Nature, 328, 143-145, 1987.

Kohlstedt, D. L., H. Keppler, and D. C. Rubie, Solubility of water in the $\alpha, \beta$, and $\gamma$ phases of $(\mathrm{Mg}, \mathrm{Fe})_{2} \mathrm{SiO}_{4}$, Contrib. Mineral. Petrol., 123, 345-357, 1996.

Kohlstedt, D. L., and S. J. Mackwell, Diffusion of hydrogen and point defects in olivine, Zeitschrift für Physikalische Chemie, 207, 147-162, 1998.

Kostenko, O., B. Jamtveit, H. Austrheim, K. Pollok, and C. Putnis, The mechanism of fluid infiltration in peridotites at Almklovdalen, western Norway, Geofluids, 2, 203-215, 2002.

Kudoh, Y., Predicted model for hydrous modified olivine (HyM- $\alpha$ ), Phys. Chem. Miner., 29, 387-395, 2002.

Kurosawa, M., H. Yurimoto, and S. Sueno, Patterns in the hydrogen and trace element compositions of mantle olivines, Phys. Chem. Miner., 24, 385-395, 1997.

Lemaire, C., S. C. Kohn, and R. A. Brooker, The effect of silica activity on the incorporation mechanisms of water in synthetic forsterite: a polarised infrared spectroscopic study, Contrib. Mineral. Petrol., 147, 48-57, 2004.

Libowitzky, E., and A. Beran, OH defects in forsterite, Phys. Chem. Miner., 22, 387-392, 1995.

Liu, Z., G. A. Lager, R. J. Hemley, and N. L. Ross, Synchrotron infrared spectroscopy of $\mathrm{OH}$-chondrodite and $\mathrm{OH}$-clinohumite at high pressure, Am. Mineral., 88, 1412-1415, 2003.

Mackwell, S. J., D. L. Kohlstedt, and M. S. Paterson, The role of water in the deformation of olivine single crystals, J. Geophys. Res., 90, 11,319-11,333, 1985.

Martin, R. F., and G. Donnay, Hydroxyl in the mantle, Am. Mineral., 57, 554-570, 1972.

Matsyuk, S. S., and K. Langer, Hydroxyl in olivines from mantle xenoliths in kimberlites from the Siberian platform, Contrib. Mineral. Petrol., 147, 413-437, 2004.

Matveev, S., H. S. C. O'Neill, C. Ballhaus, W. R. Taylor, and D. $\mathrm{H}$. Green, Effect of silica activity on $\mathrm{OH}-\mathrm{IR}$ spectra of olivine: implications for low- $a \mathrm{SiO}_{2}$ mantle metasomatism, J. Petrol., 42, 721-729, 2001.

Matveev, S., M. Portnyagin, C. Ballhaus, R. Brooker, and C. A. Geiger, FTIR spectrum of phenocryst olivine as an indicator of silica saturation in magmas, J. Petrol., doi:10.1093/petrology/egh090, 2005.

McGetchin, T. R., L. T. Silver, and A. A. Chodos, Titanoclinohumite: a possible mineralogical site for water in the upper mantle, J. Geophys. Res., 75, 255-259, 1970.
Medaris, L. G., Garnet peridotites in Eurasian ultrahigh-pressure terranes: a diversity of origins and thermal histories, Int. Geol. Rev., 41, 799-815, 1999.

Miller, G. H., G. R. Rossman, and G. E. Harlow, The natural occurrence of hydroxide in olivine, Phys. Chem. Miner., 14, 461-472, 1987.

Mosenfelder, J. L., N. I. Deligne, P. D. Asimow, and G. R. Rossman, Hydrogen incorporation in olivine from 2-12 GPa, Am. Mineral., 91, 285-294, 2006.

Paterson, M., The determination of hydroxyl by infrared absorption in quartz, silicate glasses and similar materials, Bull. Mineral., 105, 20-29, 1982.

Peslier, A.H. and J.F. Luhr, Hydrogen loss from olivines in mantle xenoliths from Simcoe (USA) and Mexico: mafic alkalic magma ascent rates and water budget of the sub-continental lithosphere, Earth Planet. Sci. Lett., 242, 302-319, 2006.

Risold, A.-C., V. Trommsdorf, and B. Grobety, Genesis of ilmenite rods and palisades along humite-type defects in olivine from Alpe Arami, Contrib. Mineral. Petrol., 140, 619-628, 2001.

Rossman, G. R., Studies of $\mathrm{OH}$ in nominally anhydrous minerals, Phys. Chem. Miner., 23, 299-304, 1996.

Rossman, G. R., C. Verdel, and E. A. Johnson (in preparation), Nanopores: an important reservoir of water in some nominally anhydrous minerals.

Smith, D., and S. Levy, Petrology of the Green Knobs diatreme and implications for the upper mantle below the Colorado Plateau, Earth Planet. Sci. Lett., 29, 107-125, 1976.

Smyth, J.R., D.J. Frost, and F. Nestola, Hydration of olivine at $12 \mathrm{GPa}$, EOS Trans. $A G U, 85(47)$, Fall Meet. Suppl., Abstract T32B-04, 2005.

Sykes, D., G. R. Rossman, D. R. Veblen, and E. S. Grew, Enhanced hydrogen and fluorine incorporation in borian olivine, Am. Mineral., 79, 904-908, 1994.

Ulmer, P., and V. Trommsdorff, Phase relations of hydrous mantle subducting to $300 \mathrm{~km}$, in Mantle petrology: field observations and high pressure experimentation: a tribute to Francis $R$. (Joe) Boyd, edited by Y. Fei, et al., pp. 259-282, Geochemical Society, Houston, Texas, 1999.

van Roermund, H. L. M., M. R. Drury, A. Barnhoorn, and A. A. de Ronde, Super-silicic garnet microstructures from an orogenic garnet peridotite, evidence for an ultra-deep ( $>6 \mathrm{GPa}$ ) origin, $J$. Metamorph. Geol., 18, 135-147, 2000.

Wirth, R., L. F. Dobrzhinetskaya, and H. W. Green, Electron microscope study of the reaction olivine $+\mathrm{H}_{2} \mathrm{O}+\mathrm{TiO}_{2} \rightarrow$ titanian clinohumite + titanian chondrodite synthesized at $8 \mathrm{GPa}, 1300$ K, Am. Mineral., 86, 601-610, 2001.

Zhao, Y.-H., S. B. Ginsberg, and D. L. Kohlstedt, Solubility of hydrogen in olivine: dependence on temperature and iron content, Contrib. Mineral. Petrol., 147, 155-161, 2004.

Jed L. Mosenfelder, California Institute of Technology, Division of Geological and Planetary Sciences, Pasadena, CA 91125-2500, USA ( jed@gps.caltech.edu) 